\title{
EL CORONAVIRUS EXPONE BRUTALMENTE LAS FALACIAS DE LA ECONOMÍA NEOCLÁSICA Y LA GLOBALIZACIÓN*
}

Steve Keen

* DOI: https://doi.org/10.18601/01245996.v22n43.02. Recepción: 04-052020, aceptación: 06-05-2020. Traducción de Alberto Supelano. Se publica con autorización del autor. Sugerencia de citación: Keen, S. E1 coronavirus expone brutalmente las falacias de la economía neoclásica y la globalización. Revista de Economía Institucional, 22(43), 17-27. Tomado del sitio web de Steven Keen Rebuilding Macroeconomics.

a Investigador distinguido, Instituto de Estrategia, Resiliencia y Seguridad (ISRS), University College London, Londres, UK [debunking@gmail.com]. 
El coronavirus expone brutalmente las falacias de la economía neoclásica y la globalización

Resumen. En este artículo se argumenta que el coronavirus es el resultado de la excesiva presión humana sobre la biosfera, y que los efectos de la pandemia que ha causado en el mundo han sido agravados por las recomendaciones de política derivadas del pensamiento económico convencional, cuyos defensores - para mantener a salvo su paradigma- argumentarán, igual que en la crisis financiera de 2008 , que la actual crisis sanitaria no era predecible.

Palabras clave: Coronavirus, pandemia; JEL: I12, I15

\section{Coronavirus brutally exposes the fallacies underlying neoclassical economics and Globalisation}

Abstract. This article argues that the coronavirus is the result of excessive human pressure on the biosphere, and that the effects of the pandemic it has caused in the world have been aggravated by policy recommendations derived from conventional economic thought, whose advocates - to keep their paradigm safe - will argue, just as in the 2008 financial crisis, that the current health crisis was not predictable.

Keywords: Coronavirus, pandemic; JEL: I12, I15

O coronavírus expõe brutalmente as falácias da economia neoclássica e da globalização

Resumo. Este artigo argumenta que o coronavírus é o resultado de pressão humana excessiva na biosfera e que os efeitos da pandemia que causou no mundo foram agravados por recomendações de políticas derivadas do pensamento econômico convencional, cujos advogados - Para manter seu paradigma seguro - eles argumentarão, assim como na crise financeira de 2008, que a atual crise da saúde não era previsível.

Palavras-chave: Coronavírus, pandemia; JEL: I12, I15 
H1 coronavirus no fue causado por el cambio climático: es obvio que se correlaciona con el cambio climático, pero "correlación no es causalidad".

Sin embargo, cuando dos tendencias se correlacionan, una de las razones puede ser que ambas son causadas por el mismo factor subyacente. En los casos del coronavirus y el cambio climático, ese factor es la carga que la humanidad industrializada ha impuesto a la biosfera de la Tierra.

Hoy, el argumento más sólido en favor de esta afirmación puede ser el caso del coronavirus, en vez del cambio climático. Bar-On et al., autores del artículo "La distribución de biomasa en la Tierra" (2018) midieron la masa relativa de las formas de vida (incluidos los virus) en la Tierra, en términos de su masa de carbono. Estimaron que los humanos, 0,06 gigatoneladas de carbono, representan casi diez veces la masa de los mamíferos salvajes (0,007 Gton) mientras que el ganado llega a casi 20 veces la masa de los humanos $(0,1 \mathrm{Gton}$, ver la gráfica 1). Si hace 100.000 años una civilización alienígena hubiese hecho una auditoría similar de la vida en la Tierra, los humanos solo habrían sido una pequeña fracción de las aproximadamente 0,1 Gton de mamíferos del planeta. Ahora, como lo resumió un medio de comunicación, los humanos y los animales que criamos para nuestro uso constituyen el 96\% de la biomasa de mamíferos del planeta (Rosane, 2018).

[arqueas $7 \mathrm{Gt} \mathrm{C}$ virus o,2 $\mathrm{Gt} \mathrm{C}$ bacterias t0 $\mathrm{Gt} \mathrm{C}$ plantas protistas hongos animales moluscos nematodos anélidos aves salvajes peces mamíferos salvajes cnidarios ganado humanos]

Gráfica 1

Biomasa de formas de vida en la Tierra por gigatoneladas de carbono

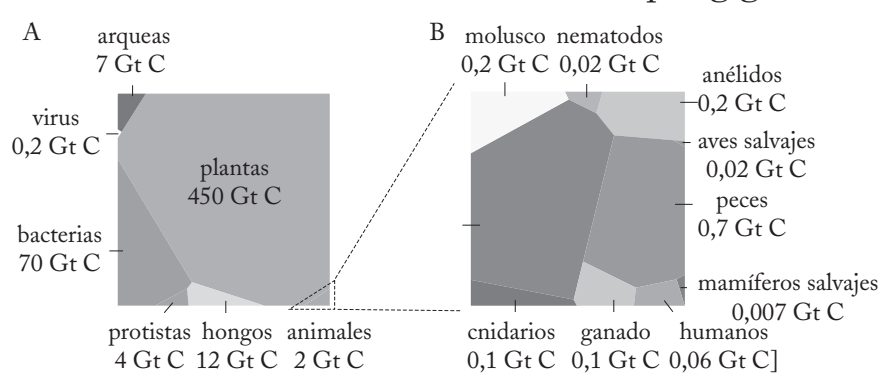

Algunas características de los humanos que nos convirtieron en el máximo depredador de este planeta son factores clave que llevaron a esta crisis, y a las muchas otras que la seguirán. 
Debido a que somos el máximo depredador, nosotros (y nuestro ganado) somos también el mejor ambiente mamífero para los patógenos. Todo virus que infecte a un gran depredador mamífero salvaje, digamos un león, tendrá una limitada existencia en la Tierra, porque el número de huéspedes está disminuyendo. El nuestro ha aumentado exponencialmente desde la industrialización, de menos de mil millones en 1800 a más de 7,5 mil millones en la actualidad.

A diferencia de otros depredadores, somos sociables entre grupos y dentro de ellos (esta sociabilidad incluye nuestras guerras, pues los vencedores ocupan el territorio de los perdedores y viven entre ellos). Los leones son sociables dentro de una manada, pero no entre ellos (aparte de que un macho mate al macho y las crías de otra manada y se haga cargo de las hembras). No es muy probable que un patógeno que infecta a una manada de leones infecte a otra. En cambio, es muy probable que un patógeno que infecta a un grupo de humanos infecte a otros grupos.

El ganado también es sociable, de modo que una enfermedad que surge en un rebaño se propagará a través suyo, de allí la muerte de casi el 50\% de los cerdos de China debido a la peste porcina del año pasado. El ganado también es de lejos el mayor huésped potencial de patógenos de los mamíferos, y es por ello que muchas de nuestras grandes enfermedades se originan en granjas de pollos, de cerdos, etc. Pero el ganado no es móvil (por decisión propia): no pueden ir de un lugar a otro si los humanos no lo desean. También es fácil eliminar a un patógeno del ganado sacrificando los rebaños que lo transportan; como se hizo con el brote de peste porcina en las granjas de cerdos de China.

Por otra parte, nosotros somos, también de lejos, la especie más móvil y sociable que haya existido, y no nos es grato matar a los nuestros, al menos en comparación con la despreocupación con la que matamos a otras especies. Así, ¿qué mejor ambiente podría haber para que se propaguen los patógenos que los humanos? Un patógeno que infecta a los humanos crecerá en número a medida que aumente nuestro número; se propagará debido a nuestra sociabilidad y se difundirá extensamente debido a nuestra movilidad industrializada.

En su brillante libro de 1994, The coming plague, Laurie Garrett advirtió que solo era cuestión de tiempo antes de que evolucionara un sucesor de la gripe española, y causara estragos en la humanidad. Garrett señaló que los patógenos evolucionan a lo largo de dos dimensiones principales: transmisibilidad y virulencia. Normalmente, un aumento en una dimensión resulta en una reducción en la otra. 
Pero, inevitablemente, evolucionaría un patógeno que sería más transmisible y más virulento.

La combinación más peligrosa es la transmisibilidad sustancial y la virulencia moderada. La transmisibilidad sustancial lleva a que un patógeno se propague rápidamente. La letalidad moderada es más efectiva que la alta letalidad, porque con una alta letalidad el patógeno puede matar a su huésped antes de que tenga la oportunidad de transmitirse. El coronavirus golpea este punto ideal evolutivo, con la peligrosa característica adicional de que puede ser transmitido por personas asintomáticas: el simple hecho de evitar a las personas evidentemente enfermas no es una estrategia para evitar el coronavirus. También es intrínsecamente infeccioso: no hemos adquirido inmunidad contra él como la adquirimos contra la influenza (el virus que Garrett esperaba que fuera la fuente de la próxima pandemia).

De modo que el peligro que Garrett anticipó hace un cuarto de siglo se ha cumplido. Si hubiéramos diseñado nuestros sistemas de salud y de producción para hacer frente a ese evento inevitable, habríamos:

- Aumentado la capacidad de nuestros sistemas de salud, y capacitado médicos y enfermeras que cubrieran con creces la demanda;

- Producido grandes cantidades de equipos de emergencia estándar, como mascarillas y ventiladores (Garrett anticipó, correctamente, que la peste venidera sería una enfermedad respiratoria);

- Hecho nuestras economías tan robustas como fuese posible ante una crisis de salud, con cadenas de suministro cortas y un énfasis en la producción local, en vez de globalizada;

- Creado sistemas gratuitos de monitoreo de la salud -de hecho, pagando a quienes se sometan a pruebas- para que pudiéramos identificar fácilmente a los portadores de la enfermedad durante una pandemia; $y$

- Extendido nuestros sistemas monetarios para financiar el gasto normal del grueso de la población en caso de una pandemia.

Por supuesto, hicimos exactamente lo contrario. En cambio hemos:

- Reducido la capacidad de nuestros sistemas de salud para enfrentar incluso problemas de salud episódicos comunes, creyendo que no gastar en infraestructura social era "ahorrar para épocas de vacas flacas";

- Diseñado un sistema económico en el que la producción se centra en los países de bajos salarios y se exporta al resto del mundo, a través de largas cadenas de suministro que, por ejemplo, involucran a 43 países en la producción de un iPhone (Petrova, 2018); y 
- Permitido que el sector privado acumule el nivel más alto de deuda corporativa y familiar de la historia, lo que ha hecho que el sector financiero sea increíblemente poderoso e increíblemente frágil al mismo tiempo.

¿Por qué? Debido principalmente a que los políticos y los burócratas siguen, por encima de todo, los consejos de los economistas. Cuando escuchan a los profesionales de la salud, lo hacen en el contexto de un presupuesto y de una dirección de la evolución social establecidos por los economistas. La asesoría de los profesionales de la salud ayuda a determinar cómo se gasta el presupuesto de salud, pero no cuán grande es ese presupuesto, ni si se administra de un modo que ayude u obstaculice el manejo de una pandemia.

Esto se debe a que, cuando los políticos son estudiantes, no estudian epidemiología, ingeniería e incluso ni matemáticas. En cambio, si estudian una disciplina analítica en la universidad, casi siempre es economía (Yi Z. Y. y Carl, N., 2018). En particular, el Reino Unido está dominado por políticos que han obtenido el título de "Filosofía, Política y Economía” en la Universidad de Oxford, como se señaló en The Guardian:

Esta formación en economía hace que los políticos y burócratas sean incapaces de entender una crisis como esta. Son, sin embargo, muy susceptibles a los consejos de los economistas. Por ello promulgaron políticas que redujeron nuestra capacidad para hacer frente a una pandemia, diseñaron sistemas de producción y distribución que amplificaron su impacto perjudicial cuando llegó, y ridiculizaron las advertencias de personas como Garrett diciendo que eran "alarmistas” y "malthusianas”. Por estas razones, la economía neoclásica tiene gran responsabilidad por la gravedad de la crisis sanitaria y económica del coronavirus.

Por supuesto, los economistas neoclásicos ridiculizarán esta afirmación. Algo que aprendí en cincuenta años de lucha contra estos bastardos bien intencionados pero despistados es que son excelentes para darse crédito cuando el sistema económico funciona bien, pero se apresuran a desviar las críticas fingiendo impotencia cuando surge una crisis. Después de ella, recurren alegremente a su explicación favorita de por qué no podían haber visto venir la Gran Crisis Financiera de 2007, causada por un "shock exógeno". Así lo atestiguan los pronunciamientos de Ben Bernanke antes y después de la crisis financiera global:

- Antes de ella, Bernanke se atribuyó el crédito (en nombre de la profesión y de la Reserva Federal) por lo que llamó la "Gran Moderación": 
Las recesiones se han vuelto menos frecuentes y más leves, y la volatilidad trimestral de la producción y el empleo también ha disminuido significativamente. Las fuentes de la Gran Moderación siguen siendo un tanto controvertidas, pero como he argumentado en otra parte, existe evidencia de la opinión de que un mejor control de la inflación ha contribuido en gran medida a este cambio positivo en la economía (Bernanke, 2004);

- Después de ella, absolvió a la "ciencia económica” de cualquier culpa por la crisis:

¿Estas fallas de los modelos macroeconómicos estándar significan que son irrelevantes o al menos significativamente defectuosos? Creo que la respuesta es un no, con salvedades. Los modelos económicos solo son útiles en el contexto para el que son diseñados. La mayoría de las veces, incluso durante las recesiones, la grave inestabilidad financiera no es un problema. Los modelos estándar fueron diseñados para estos periodos de no crisis, y han demostrado ser muy útiles en ese contexto. En particular, fueron parte del marco intelectual que ayudó a lograr una baja inflación y estabilidad macroeconómica en la mayoría de los países industriales durante las dos décadas que comenzaron a mediados de los ochenta (Bernanke 2010).

Esto no se debe a que los economistas neoclásicos sean intrínsecamente mentirosos u oportunistas: se debe a que creen sinceramente que su paradigma describe el capitalismo con exactitud y, en consecuencia, a que no pueden entender que no es así. De modo que cada vez que su paradigma falla, como en 2007, buscan razones por las que realmente no falló, como la de que la crisis no se podía predecir, y que criticarlos por no anticiparla era como criticar a un matemático por no predecir los números ganadores de la lotería de la próxima semana (Miles, 2017).

Como dije en respuesta a ese comentario en su momento, esta es charlatanería neoclásica. No difiere del comentario de un astrónomo ptolemaico que le hubiera dicho a Halley que no podía predecir la fecha del regreso del cometa que lleva su nombre, porque en el paradigma ptolemaico, los cometas eran fenómenos atmosféricos impredecibles. Igual que en el caso de los astrónomos ptolemaicos, lo que falla es el paradigma neoclásico, y no los críticos que lo rechazan ${ }^{1}$.

${ }^{1}$ Existe un paradigma alternativo (representado por personas como el fallecido Wynne Godley, Steve Keen, Michael Hudson, Ann Pettifor, Dirk Bezemer y varios otros) en el que la deuda privada y su tasa de cambio anual (que yo llamo crédito) desempeñan un papel esencial en macroeconomía, y que hacen inevitable una crisis. Eso es lo que sucedió realmente, pero debido a que la deuda privada y el crédito no desempeñan ningún papel en el paradigma neoclásico, se siguen ignorando los datos a ese respecto. Esto no se debe a que no haya datos disponibles o no sean confiables, sino a que simplemente no se ajustan a su manera de ver el mundo. Por ello se igno- 
De modo que antes de que empiecen a crear una niebla de ofuscación con respecto a esta crisis, salgámosles al paso:

- Después de esta crisis, y quizá incluso durante ella, dirán que se ha exagerado la influencia de la economía en los diseñadores de política: los políticos tomaron por su propia cuenta la decisión de recortar la financiación para la salud y demás políticas sociales.

Pero si es así, ¿por qué Paul Samuelson, el autor del texto de economía más influyente después de la Segunda Guerra Mundial, y el padre verdadero de la economía moderna², declaró: "no me importa quién escribe las leyes de un país -o elabora su tratados avanzados- si puedo escribir sus textos de economía”? Sabía que las ideas económicas de una época determinan en alto grado lo que hacen sus legisladores y administradores. Sus descendientes hoy también lo saben. El artículo de 1995 que cita esta frase describe el ascenso del omnipresente texto de Gregory Mankiw, y afirma que fue el más prometedor de varios "proselitistas" que "aprovechan la oportunidad de moldear la mente de la próxima generación de líderes políticos, ejecutivos, creadores de imagen y otros miembros de la élite estadounidense" (Nasar, 1995).

Este moldeamiento ocurre principalmente en el curso de economía de primer año que toma la gran mayoría de líderes políticos y burócratas modernos, en cursos como Econ 101 en universidades estadounidenses y en programas de grado como Filosofía, Política y Economía (PPE) en el Reino Unido. La economía convencional es la principal herramienta analítica que aprenden - muy pocos aprenden matemáticas o ingeniería, y mucho menos microbiología- y es la caja de herramientas a la que primero recurren cuando surge un nuevo problema de política ${ }^{3}$.

ran los datos que muestran que las tres principales crisis de Estados Unidos fueron impulsadas por un colapso del crédito (ver la gráfica 2). Y también se ignora la correlación abrumadora entre crédito y desempleo (ver la gráfica 3).

${ }^{2}$ Las dos corrientes de la macroeconomía dominante -los "nuevos clásicos", defensores extremos del libre mercado que en nada se parecen a la escuela de pensamiento económico clásico real, y los “nuevos keynesianos”, defensores moderados del libre mercado cuyas ideas nada se asemejan a las ideas de Keynes- utilizan las herramientas analíticas que inventó Samuelson para crear lo que llamó "síntesis neoclásica-keynesiana". Lo que los críticos desinformados menosprecian como "economía keynesiana" realmente se debería llamar "economía samuelsoniana.

${ }^{3}$ Un colega, el historiador Chris Shiels, quien escribió una brillante crítica de la privatización del agua en Australia llamada Water's Fall, solía trabajar en el Departamento del Primer Ministro y el Gabinete cuando Paul Keating era el Primer Ministro de Australia. Shiels describió el pánico que había entre el personal cuando surgía un tema nuevo, que solo se disipaba 
En consecuencia, la perspectiva de las demás disciplinas no merece una mención en comparación con el impacto de la disciplina económica.

- Los economistas afirmarán que es imposible integrar todos los aspectos de la sociedad en su análisis, de modo que deben hacer "suposiciones simplificadoras" que omiten, por ejemplo, el sistema de salud, la dinámica de la población, etc. en su análisis.

Esto ha sido falso durante sesenta años, desde cuando el brillante ingeniero Jay Forrester inventó la Dinámica de Sistemas: un método que hace posible el análisis de múltiples sistemas entrelazados que operan fuera del equilibrio y tienen efectos de retroalimentación. Ese método aún existe, pero ha recibido muy poco apoyo para desarro1larlo. ¿Por qué? Porque los economistas, $-\mathrm{y}$ en este caso, en especial William Nordhaus, ganador del "Premio Nobel de Economía" de 2018- desacreditaron este método sin entenderlo. Los economistas, con su método de equilibrio, siguieron recibiendo la mayor parte de la financiación, y la dinámica de sistemas poco ha avanzado debido su muy escasa financiación.

\section{Gráfica 2}

Deuda privada y su variación anual en Estados Unidos, 1837-2020

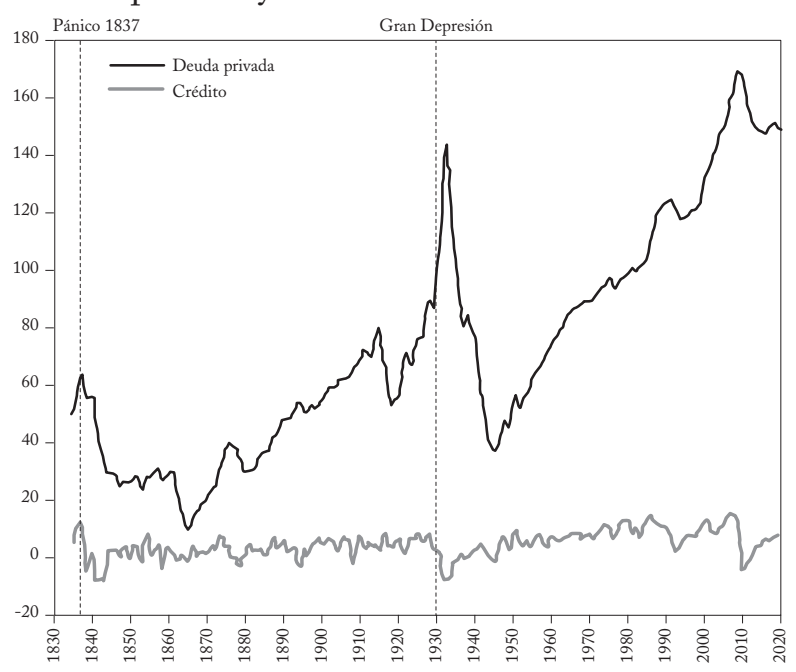

Fuente: datos del BIS y de la OCDE.

cuando alguien sugería un enfoque que se podía encontrar en un texto de economía de primer año. Como casi todos los asesores compartían ese paradigma, la idea era adoptada fácilmente. 
Los economistas no pueden eludir la responsabilidad por el hecho de que la producción esté fuertemente globalizada, por el apoyo de los economistas al libre comercio frente a la autosuficiencia, como por su apoyo a la relocalización de la producción, de Occidente al Tercer Mundo. En consecuencia, una enfermedad como esta golpeó al planeta enero cuando golpeó a un solo país, aunque ayudó que el único país inicialmente fuera China, a la que se subcontrató gran parte de la producción mundial.

Después de esta crisis, tenemos que revocar la carta blanca que se dio a los economistas para remodelar la economía a la imagen de sus libros de texto. Es hora de dejar que las ciencias reales manejen el impacto de la humanidad sobre el planeta.

Gráfica 3 Crédito y desempleo en Estados Unidos desde 1990

(Correlación 0,85)

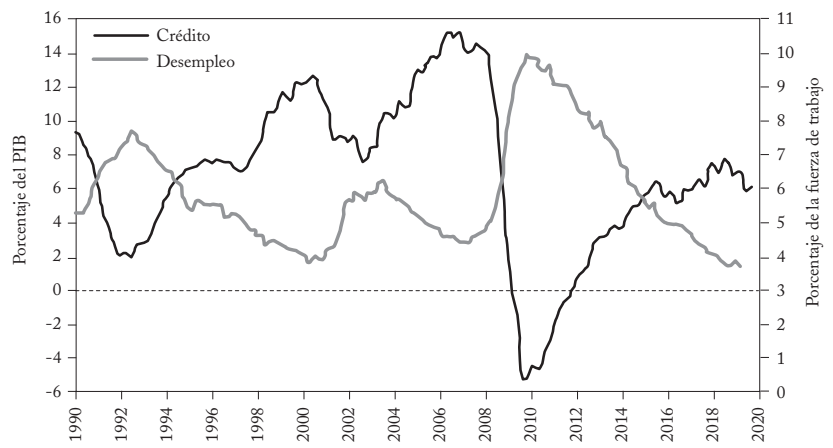

Fuente: datos del BIS y de la OCDE.

\section{REFERENCIAS BIBLIOGRÁFICAS}

Bar-On, Y. M. Phillips, R. y Milo, R. (2018). The biomass distribution on Earth. PASS, 115(25), 6509-6511, [https://www.pnas.org/content/ pnas/115/25/6506.full.pdf].

Bernanke, B. S. (1979). What have we learned since, [https://www. federalreserve.gov/Boarddocs/Speeches/2004/20041008/default.htm].

Bernanke, B. S. (2010). Implications of the financial crisis for economics, [https://www.federalreserve.gov/newsevents/speech/bernanke20100924a.htm].

Garrett, L. (1994) The coming plague. Newly emerging diseases in a world out of balance. Nueva York: Straus and Giroux.

Yi Z., Y. y Carl, N. (2018). Are PPE graduates ruining Britain? MPs who studied it at university are among the most pro-remain [https:// blogs.lse.ac.uk/brexit/2018/11/14/mps-who-studied-ppe-at-universityare-among-the-most-pro-remain/]. 
Miles, D. (2017). Andy Haldane is wrong: there is no crisis in economics, [https://www.ft.com/content/f1c1dd00-d812-11e6-944be7eb37a6aa8e].

Nasar, S. (1995). A hard act to follow? Here goes, [https://www.nytimes. com/1995/03/14/business/a-hard-act-to-follow-here-goes.html.

Petrova, M. (2018). We traced what it takes to make an iPhone, from its initial design to the components and raw materials needed to make it a reality, [https://www.cnbc.com/2018/12/13/inside-apple-iphonewhere-parts-and-materials-come-from.html].

Rosane, O. (2018). Humans and big ag livestock now account for 96 percent of mammal biomass, [https://www.ecowatch.com/biomasshumans-animals-2571413930.html]- 